\title{
Alternative Fuel Research in Fischer-Tropsch Synthesis
}

\author{
Angela D. Surgenor, Jennifer L. Klettlinger, Chia H. Yen, and Leah M. Nakley
}

\begin{abstract}
NASA Glenn Research Center has recently constructed an Alternative Fuels Laboratory which is solely being used to perform Fischer-Tropsch (F-T) reactor studies, novel catalyst development and thermal stability experiments. Facility systems have demonstrated reliability and consistency for continuous and safe operations in Fischer-Tropsch synthesis.

The purpose of this test facility is to conduct bench scale Fischer-Tropsch (F-T) catalyst screening experiments while focusing on reducing energy inputs, reducing $\mathrm{CO}_{2}$ emissions and increasing product yields within the F-T process. Fischer-Tropsch synthesis is considered a gas to liquid process which reacts syn-gas (a gaseous mixture of hydrogen and carbon monoxide), over the surface of a catalyst material which is then converted into liquids of various hydrocarbon chain length and product distributions ${ }^{1}$. These hydrocarbons can then be further processed into higher quality liquid fuels such as gasoline and diesel.

The experiments performed in this laboratory will enable the investigation of F-T reaction kinetics to focus on newly formulated catalysts, improved process conditions and enhanced catalyst activation methods. Currently the facility has the capability of performing three simultaneous reactor screening tests, along with a fourth fixed-bed reactor used solely for cobalt catalyst activation.
\end{abstract}

Index Terms-Alternative Fuels, Catalyst, Fischer-Tropsch, NASA, Reaction Kinetics, Syngas, Synthesis, Thermal Stability, JFTOT, ASTM D3241.

\section{NOMENCLATURE}

Fischer-Tropsch Synthesis, Alternative Fuels, JFTOT (Jet Fuel Thermal Oxidation Test), CAER (Center for Applied Energy Research)

This effort is supported by the NASA Fundamental Aeronautics Subsonic Fixed Wing project.

A. D. Surgenor is with the Combustion Branch at NASA Glenn Research Center, Cleveland, OH 44135 USA ( email: angela.d.surgenor@ nasa.gov)

J. L. Klettlinger is with the Combustion Branch at NASA Glenn Research Center, Cleveland , OH 44135 USA (email: j.klettlinger@nasa.gov)

C. H. Yen is with the University of Toledo, Cleveland, $\mathrm{OH} 44135$ (email: chia.h.yen@nasa.gov)

L. M. Nakley is with the Facilities Division with Sierra Lobo Inc at NASA Glenn Research Center, Cleveland, OH 44135 (email: leah.m.nakley@nasa.gov)

\section{INTRODUCTION}

Alternative fuels research plays an important role in emissions reduction in the effort to decrease the country's energy dependencies. ${ }^{2,8}$ Rising crude oil prices, energy independence, fluctuating global climate changes, and improving combustion performance while meeting advanced emission requirements are all of major concern in the area of commercial aviation. Reducing capital costs associated with synthetic jet-fuel production from non-conventional sources is also of concern. NASA Glenn's Alternative Fuel research effort is primarily focusing on improving combustion performance and reducing $\mathrm{CO}_{2}$ emissions in advanced jet engine designs that could use alternative type fuels including Fischer-Tropsch (F-T) fuels. The Fischer-Tropsch process provides the ability to convert the nation's natural energy resources such as coal, natural gas, and biomass into a cleaner and more economical alternative to traditional commercial jet fuel ${ }^{1}$.

In the 1920's the F-T process was first developed by Franz Fischer and Hans Tropsch at the Kaiser Wilhelm Institute for Coal Research in Germany prior to World War II. This process was initially developed to help Germany's need for fuel while in the middle of a petroleum shortage. The initial process for producing F-T fuels was focused on converting coal into synthetic fuel, since Germany had an abundant coal supply ${ }^{3}$.

F-T fuel composition differs from petroleum-based, conventional commercial jet fuel because of differences in feedstock and production methodology ${ }^{1}$. F-T jet fuel is expected to be more stable than conventional jet fuel at elevated temperatures, thus offering a potentially cleaner burning fuel with superior thermal stability characteristics. A key property that limits the use of conventional fuels in modern military aircraft applications is thermal stability. Thermal instability of aviation fuel can result in several effects that are detrimental to the operation of the aircraft. The most frequently cited effects are reduced efficiency of fuel-oil heat exchangers, fouling of fuel control units, and fuel injector blockage ${ }^{4}$.

F-T jet fuel is comparable to Jet-A fuel but has been shown to have superior properties in engine testing. Combustion research performed with F-T fuels has proven to significantly reduce particulate emissions without effecting engine performance. F-T fuel also has excellent thermal stability at elevated temperatures, and also has superior low temperature properties. Since F-T fuels contain little to no 
aromatics or sulfur contaminants, they are typically considered of higher quality, and have shown to burn cleaner than petroleum-based fuels. This in turn results in lower emission concentrations of $\mathrm{CO}_{2}$, unburned hydrocarbons, and harmful particulates being released into the atmosphere ${ }^{3}$.

The Fischer-Tropsch process has three distinct steps: gasification, synthesis, and product upgrade. The gasification step can produce syngas from various hydrocarbon resources. Synthesis involves the conversion of syngas to syn-crude oil and the product upgrade processes the syn-crude and separates it into useable liquid fuels. Figure 1 shows the overall F-T process. NASA Glenn is primarily focusing on the "F-T Synthesis" step of the overall F-T process by optimizing novel catalysts to increase reactor yields, reduce energy inputs, and to reduce $\mathrm{CO} 2$ emissions.

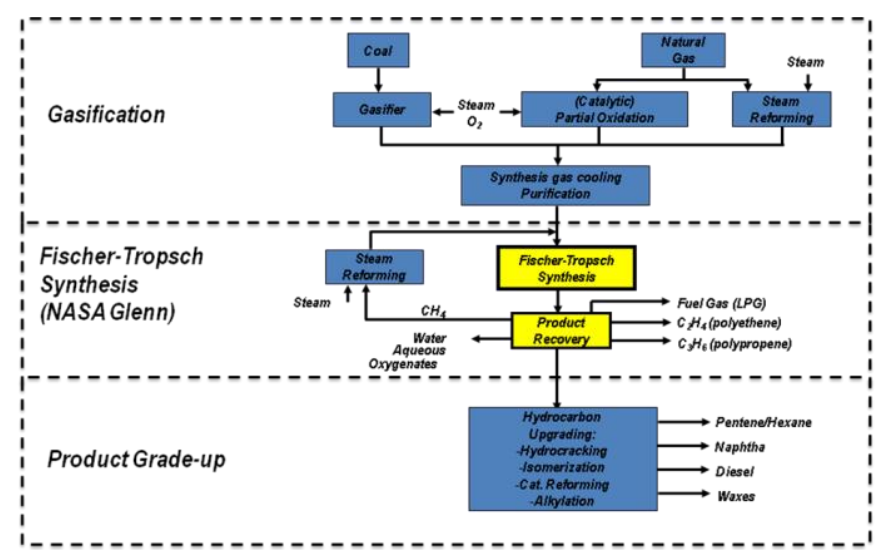

Figure 1: Overall F-T process

The synthesis reaction produces a wax (paraffin), light oil (olefin) and water product. Equation 1 shows the F-T reaction chemistry.

$$
\begin{aligned}
& \text { Fischer Tropsch reaction: } 2 \mathrm{H}_{2}+\mathrm{CO} \rightarrow-\mathrm{CH}_{2}-+\mathrm{H}_{2} \mathrm{O} \\
& \begin{array}{lrl}
\text { Paraffins } & (2 n+1) \cdot H_{2}+n \cdot C O & \Rightarrow \mathrm{C}_{n} H_{2 n+2}+n \cdot H_{2} \mathrm{O} \\
\text { Olefins } & 2 n \cdot H_{2}+n \cdot \mathrm{CO} \Rightarrow \mathrm{C}_{n} \mathrm{H}_{2 n}+n \cdot \mathrm{H}_{2} \mathrm{O} \\
\text { Water gas shift reaction } & \mathrm{CO}+\mathrm{H}_{2} \mathrm{O} \Leftrightarrow \mathrm{CO}_{2}+\mathrm{H}_{2}
\end{array}
\end{aligned}
$$

Equation 1: F-T reaction chemistry

NASA Glenn is currently focusing on creating and testing cobalt and iron type catalysts. Cobalt catalyst are supported with, but not limited to various concentrations of $\mathrm{Al}_{2} \mathrm{O}_{3}, \mathrm{SiO}_{2}$, and $\mathrm{TiO}_{2}$. Textural promoters are also used for cobalt catalysts such as $\mathrm{Zr}$, La, B, and $\mathrm{K}$ to increase dispersion of clusters, improve attrition resistance, enhance sulfur tolerance and electronically modify the active metal sites. Reduction promoters such as $\mathrm{Pt}, \mathrm{Ru}, \mathrm{Re}, \mathrm{Au}$ and $\mathrm{Ag}$ are also used to catalyze the cobalt reduction to lower activation temperatures, and to remove excessive hydrogen from the promoter surface. Present day iron catalyst formulations are not supported and are an active research area to improve on mechanical strength without performance degradation. Iron catalysts are promoted by metals such as alkali, and alkaline metals, (ie: potassium), transition metals (ie: copper) and silica.

Although there are many positive aspects of F-T fuels, there are also technical, economic, and strategic challenges that come along with this type of fuel. Challenges that still need to be overcome include the interchangeability of F-T fuels with crude-oil derived kerosene-type fuels; high energy inputs; high production of $\mathrm{CO}_{2}$ emissions; sealing compatibility of fuel systems already conditioned in crude-oil derived kerosene-type fuels; demand and supply of F-T fuels at prices comparable to crude-oil derived kerosene-type fuels; and the modification of existing fuel specifications to allow for general approval of F-T kerosene-type fuels 5 .

NASA Glenn is working on performing this F-T research to provide independent catalyst screening tests, verify catalyst integrity, and to develop and produce in house catalysts to further the development of new and improved alternative type fuels. This standardized test facility also enables external collaborations to be performed along with publically releasing results for in-house catalyst formulations. NASA Glenn has recently completed baseline catalyst studies and is now in the process of starting up with new novel catalysts from external collaborations and in-house formulations. This paper mainly describes the test facility and its capabilities and also gives a brief description of a baseline Cobalt test and its conversion results.

\section{FACILITY RESEARCH SYSTEMS}

The alternative fuels research hardware consists of three 1-liter Continuously Stirred Tank Reactors (CSTRs), and a fixed-bed activation reactor. Inside of these reactors, gaseous hydrogen and carbon monoxide are mixed in the presence of a catalyst while heated under pressure to cause the F-T synthesis reaction. Current operating pressures for the CSTRs are limited to $450 \mathrm{psig}$ at $280^{\circ} \mathrm{C}$, based on the system designs employed by Glenn Research Center and by the operational requirements for running F-T synthesis studies. Figure 2 shows a CSTR unit ${ }^{6}$.

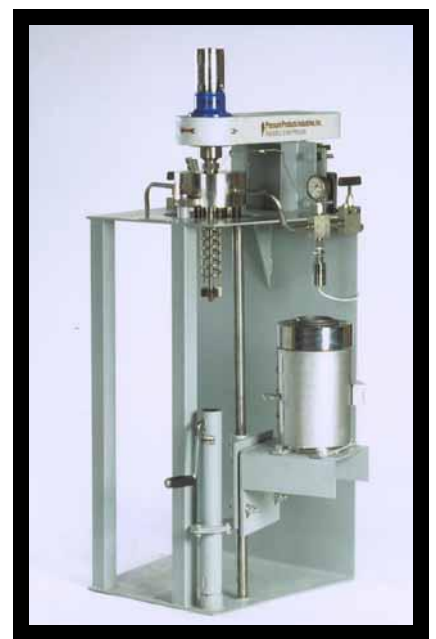

Figure 2: One liter capacity CSTR $^{6}$

A block flow diagram in figure 3 depicts the F-T synthesis process configuration. Each integrated reactor 
system includes individually controlled gas feed systems, a continuous stirred reactor unit, and individual sampling ports for removing refinery gas, liquid, and molten wax samples. Each CSTR is equipped with a dedicated programmable logic controller (PLC) for control and operation monitoring.

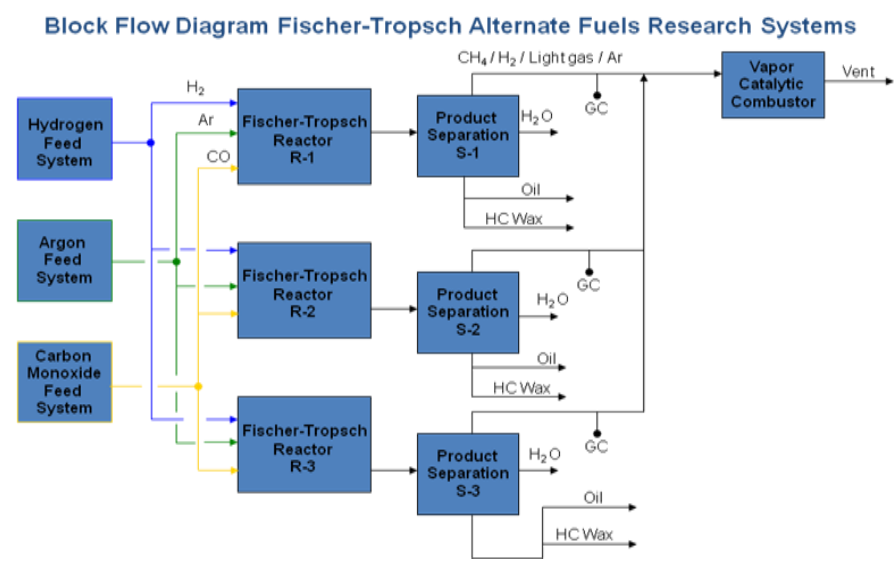

Figure 3: Block Flow diagram of F-T synthesis process configuration

For a typical test, either an iron or cobalt catalyst is inserted into a reactor with either Polywax 3000 or Polywax $500{ }^{7}$. The reactor is then closed up while introducing an inert purge such as argon or nitrogen and heat. The reactor is then pressurized to a designated pressure accompanied by agitation and syngas ( $\mathrm{CO}$ and $\mathrm{H}_{2}$ ). Typical start up agitation is operated at $100 \mathrm{rpm}$ solely for catalyst activation purposes, then increased to $500 \mathrm{rpm}$ during a test but can be increased up to $1250 \mathrm{rpm}$ if desired.

A hollow agitator shaft located inside of a reactor is used to allow the vapor phase product to be re-circulated from top to bottom in the reactor. There are two sets of agitator blades on the shaft. The first set of pitched impellers is equally level with the gas/liquid product interface to force downward gas action and to reduce foaming. The second set of impellers consists of six vertical turbine blades located at the bottom of the shaft. A gas feed mixture consisting of $\mathrm{CO}, \mathrm{H}_{2}$, and $\mathrm{N}_{2}$ is fed into the reactor below the turbine blades to maximize contact and to break up gas feeds into small diameter bubbles. An internal baffle is installed in the reactor to improve contact efficiency and to avoid swirl ${ }^{3}$.

Liquid product draw-off is taken from the top of the reactor liquid volume across a sintered metal filter. The filter selection is based on the catalyst to be tested. Each F-T reactor assembly has three stainless steel cylindrical traps installed downstream of the reactors, which are used to collect F-T liquid products as three different fractions including molten waxes, light oil and water condensate. Each trap is $500 \mathrm{cc}$ in capacity. Two traps are heated with electric heat tracers which are controlled by the reactor PLCs at the following conditions: hot trap at $200{ }^{\circ} \mathrm{C}$ (wax); warm trap at $100{ }^{\circ} \mathrm{C}$ (light oil). Water by-product is collected in the cold trap which is wrapped with a copper cooling coil where chilled ethylene glycol is circulated to maintain an internal temperature of $0{ }^{\circ} \mathrm{C}$. Liquid sample level is maintained inside the reactor by manually drawing off liquid samples daily. To prevent wax from plugging the sample lines, all liquid lines are heated with heat tracing tape to approximately $175{ }^{\circ} \mathrm{C}$. Figure 4 shows a wax sample of cobalt and iron product. Figure 5 shows F-T Light Oil Product Sample.

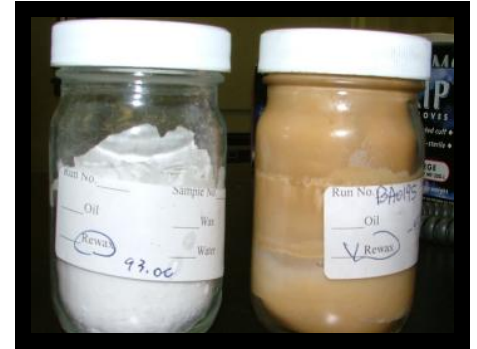

Figure 4: Cobalt wax product (left), Iron wax product (right)

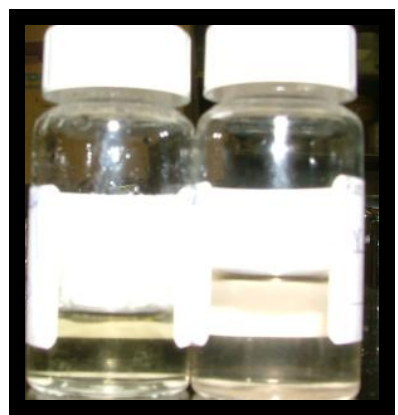

Figure 5: F-T Light Oil Product Sample

Fischer-Tropsch research consists of long duration tests which run continuously 24 hours a day, 7 days a week. Once F-T testing is initiated, the facility runs in an automated, unattended mode with the exception of daily sample collection.

\section{GAS ANALYSIS SYSTEMS}

The Gas Analysis equipment is located inside of a miniature laboratory located inside of the test facility. Gas analysis equipment consists of an Agilent 3000A Micro Gas Chromatograph (Micro GC) and two Agilent 6890 Gas Chromatographs (GCs). The Micro GC is used to analyze refinery gas samples taken directly from the F-T reactors on a continuous basis. One of the Agilent 6890 GCs is designated for oil analysis, and another is designated for wax analysis.

The gas, liquid, and molten wax samples taken from the F-T reactors are thoroughly analyzed by GCs. The GC units separate and identify compounds found in the daily solid, liquid and gas samples. The chemical compositions and quantities are used to study the overall mass balance, product distribution, and reaction kinetics. The gas chromatographs are capable of measuring compositions of light refinery gas mixtures $\left(\mathrm{H}_{2}, \mathrm{CO}, \mathrm{CH}_{4}, \mathrm{C}_{1}-\mathrm{C}_{4}, \mathrm{CO}_{2}\right.$, and $\left.\mathrm{N}_{2}\right)$, light oils $\mathrm{C}_{4}-$ $\mathrm{C}_{44}$, and heavy hydrocarbons $\mathrm{C}_{11}-\mathrm{C}_{80}$ (alkanes and alkenes). ${ }^{3}$ Figure 6 shows an Agilent 3000A Micro GC, and Agilent 6890 GC. 


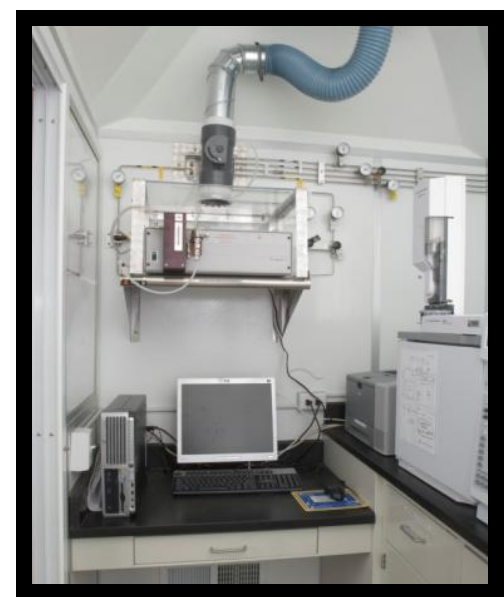

Figure 6 : Agilent 3000A Micro GC and Agilent 6890GC

\section{FIXED BED REACTOR}

The fixed-bed reactor designed by NASA GRC is based on requirements of a similar unit used by the Center for Applied Energy Research at the University of Kentucky ${ }^{9}$. This separate reactor is used for the activation of cobalt catalysts due to the fact that cobalt will immediately oxidize when exposed to air. Cobalt catalysts need to be activated and transferred to the CSTR in an inert environment. NASA Glenn has prepared a procedure to encapsulate the activated cobalt catalyst in a wax mold under inert conditions before inserting it into the CSTR reactor. Since iron catalysts do not oxidize readily in air, they are activated directly in the CSTR.

The fixed-bed reactor is designed to process catalyst materials up to $225 \mathrm{psig}$ and $430^{\circ} \mathrm{C}$ with controlled flows of gaseous hydrogen, carbon monoxide, and either argon or nitrogen as an inert gas. The average amount of catalyst loaded into the reactor is approximately10-20 grams, although the amount varies according to the test parameters. The reactor is capable of holding approximately 50 grams of catalyst depending on catalyst density. Figure 7 shows pictures of the fixed-bed reactor.

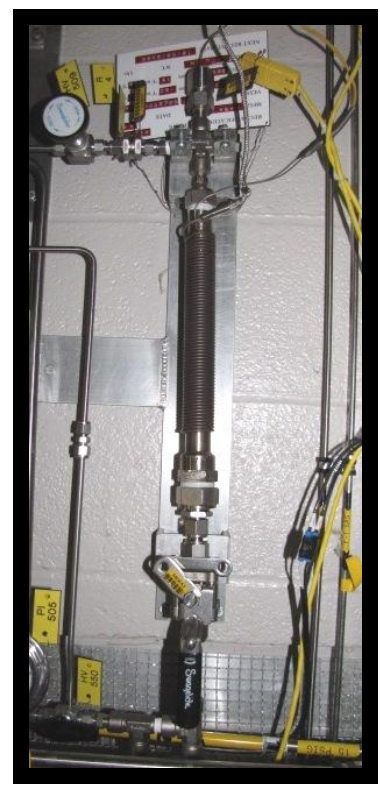

Figure 7: Fixed-bed reactor
The reactor is fabricated from a 1" OD, seamless 316 Stainless Steel tube with a wall thickness of 0.083 " and is 12 " long. A catalyst bed is supported by packed glass wool that is inserted inside of the reactor and is replaced for every test. The reactor is heated by an external electric mighty-band coil heater rated up to $940 \mathrm{~W}$.

The reactor instrumentation monitors reactor internal and wall temperatures along with pressure. Two type $\mathrm{K}$ thermocouples are inserted internally from the bottom of the reactor and are at fixed lengths. One thermocouple is near the bottom of the catalyst bed ( 1//4" above the glass wool), while the other is near the center of catalyst bed. Multiple thermocouple locations verify that the catalyst bed is uniformly heated to enable full catalyst activation. Figure 8 shows a diagram of the fixed-bed reactor with glass wool and catalyst loading. Typical Cobalt activation takes approximately 18 hours to complete. Cobalt catalysts are then encapsulated in Polywax $500^{8}$ prior to testing in a CSTR.

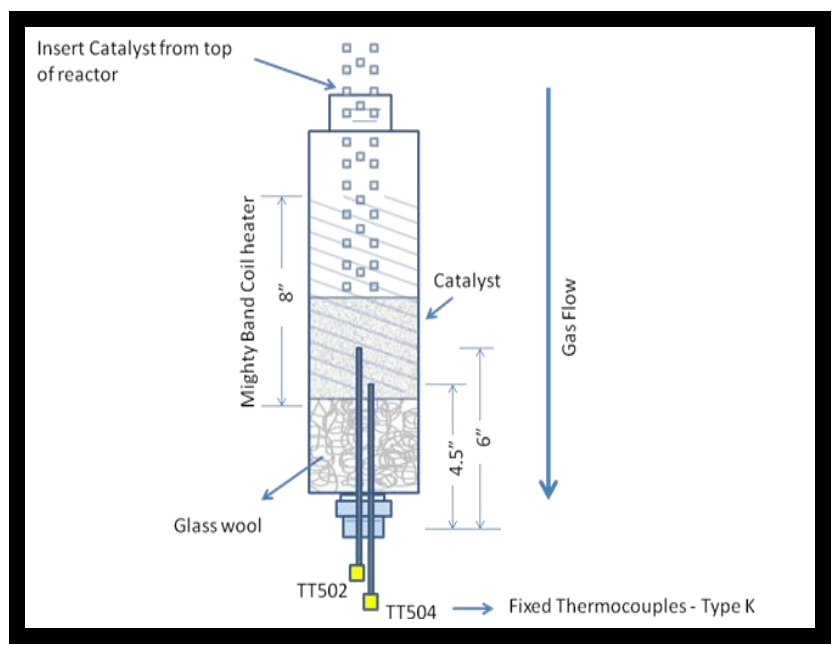

Figure 8: Fixed-bed reactor with glass wool and catalyst loading.

\section{CATAlytic COMBUStOR}

A catalytic combustor system is installed on the exit side of the reactors to oxidize refinery gases generated during the Fischer-Tropsch reaction prior to venting into the atmosphere. The combustor system is an in-house GRC design which has been successfully utilized in other facilities at NASA Glenn. This combustor takes electrically preheated air from the 125 psig facility shop air system and mixes it with the refinery gases prior to the introduction into the catalytic combustor. The combustor operating temperature is controlled nominally between $750-850{ }^{\circ} \mathrm{C}$ by varying the air feed flow that is sent to the combustor. The percent excess air used in the oxidation process ranges from $480-540 \%$ (above stoichiometric). The combustor exhaust gases are air quenched down to $150-260^{\circ} \mathrm{C}$ prior to release into the atmosphere through the facility vent stack. The combustor operates below 15 psig and is less than 6 " in diameter. This gas clean-up system effectively eliminates $\mathrm{CO}, \mathrm{CH}_{4}$, and residual light hydrocarbon emissions for a more environmentally friendly discharge into the atmosphere. Figure 9 shows the catalytic combustor. ${ }^{3}$ 


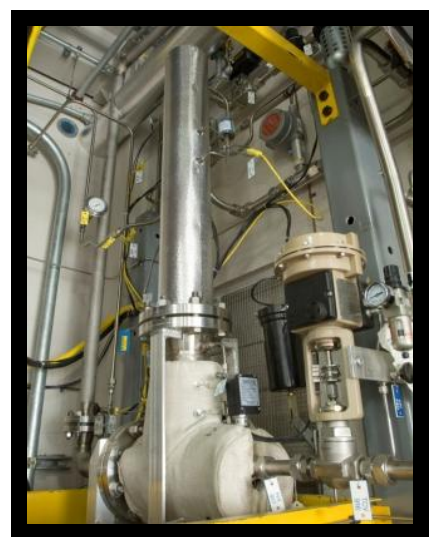

Figure 9: Catalytic Combustor

\section{CURRENT RESEARCH IN F-T PROCESS}

NASA Glenn has conducted both cobalt and iron baseline catalyst screening tests to verify system readiness and mechanical stability. Multiple baseline test results have been compared with those of the University of Kentucky and have shown to follow similar trends for both $\mathrm{CO}$ and $\mathrm{H} 2$ conversion. Chart 1 and 2 show the $\mathrm{CO}$ and $\mathrm{H} 2$ conversion test results from a Cobalt baseline test compared to the results given by the University of Kentucky. As can be seen, the results are not exact but follow a similar trend compared to the results from the University. Variances in these results were caused by mechanical and electrical system malfunctions during the tests along with glitches in the gas chromatograph system as well. All of the system glitches have now been resolved and all three reactors are fully operational and are in a continuous test mode.

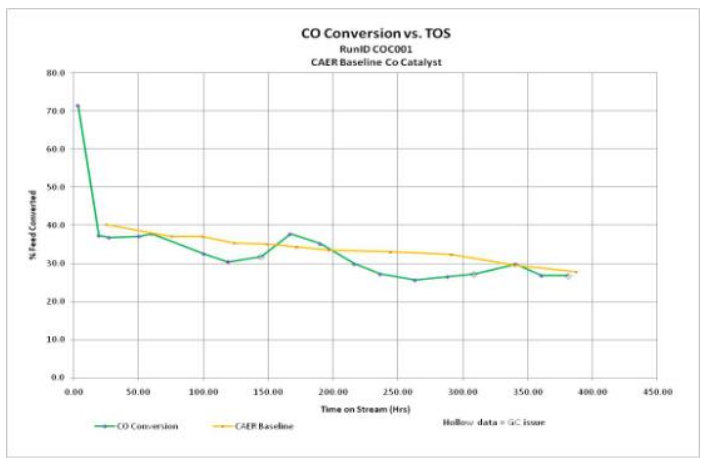

Chart 1: CO conversion comparison for Co baseline test

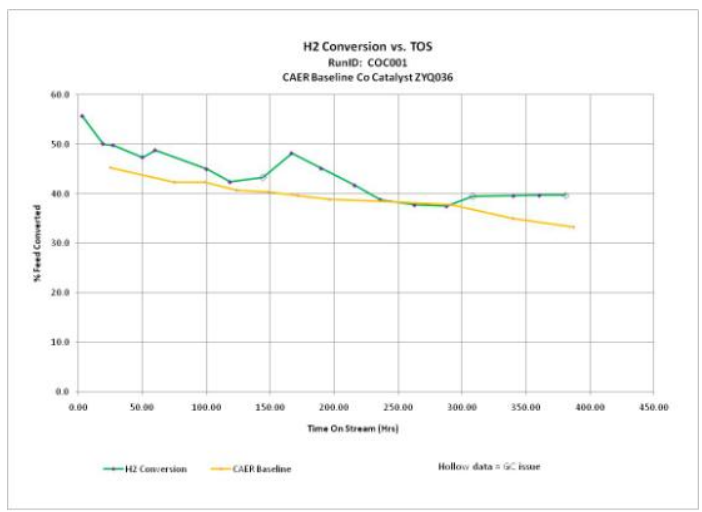

Chart 2: $\mathrm{H} 2$ conversion comparison for Co baseline test
Current research is being performed on catalysts provided by the University of Toledo along with in-house catalyst formulations. NASA Glenn has its own catalysis laboratory in which newly formulated catalysts can be created and analyzed. NASA Glenn also has collaborative efforts in place with the University of Kentucky and the University of Toledo for producing new and improved novel catalysts to be tested in the alternative fuels laboratory.

\section{Hot LIQUID PROCESS SIMULATOR}

One method to quantify the fuel's thermal stability is to measure the fuel's "Breakpoint" in accordance with the ASTM D3241specification test known as Jet Fuel Thermal Oxidation Test (JFTOT). JFTOT assesses fuel thermal degradation by two means: one by the heated tube's discoloration due to hydrocarbon coating, and the other by determining a pressure drop (DP) due to particulate formation. ${ }^{10}$

The Alternative Fuels Laboratory houses a Hot Liquid Process Simulator (HLPS), model HLPS-400 manufactured by Alcor ${ }^{11}$. The HLPS analyzer is used to determine fuel breakpoint according to JFTOT. Breakpoint can be defined as the highest temperature at which a fuel can pass the JFTOT. Currently, the JFTOT required temperature rating of fuel to meet aviation standards is $260{ }^{\circ} \mathrm{C} .{ }^{10}$

For the JFTOT, aerated fuel flows at $3 \mathrm{cc} / \mathrm{min}$ over an electrically heated tube at a preset temperature for $150 \mathrm{~min}$. At the end of the test, the tube is removed from the test stand and visually examined. The tube is inserted into a Visual Tube Rater (VTR) which is an internally lit black box consisting of a standard ASTM color chart. The tube is optically compared to the color chart and is assigned a color number ranging from 1 to 4 ( 1 is metallic silver, 2 is slightly tan, 3-4 are shades of brown). A tube color of 3 or less constitutes a pass. Fuel degradation can also form particulates which are collected on a filter, and will lead to a higher filter pressure drop (DP) over the test period. $25 \mathrm{mmHg}$ is the maximum pressure drop permitted over the full $150 \mathrm{~min}$ test for a fuel to pass the test. Both the tube color $(<=3)$ and the DP $(<=25 \mathrm{mmHg})$ are required for passing the JFTOT; if either fails, the JFTOT is considered a failed test. To determine the fuel's breakpoint, the fuel is tested at $5{ }^{\circ} \mathrm{C}$ increments starting from $260^{\circ} \mathrm{C}^{10}$ and is continued until a failure occurs. The breakpoint value will be at the temperature with the highest passable JFTOT temperature. Typical tests use approximately $600 \mathrm{ml}$ of fuel per test, and take approximately four hours to assess one temperature point. The number of tests needed per fuel sample depends on what fuel is being tested, and where the actual breakpoint temperature is found. ${ }^{10}$ Figure 10 shows a diagram of the Hot Liquid Process Simulator. Figure 11 shows a diagram of fuel flowing over a heated JFTOT tube. 


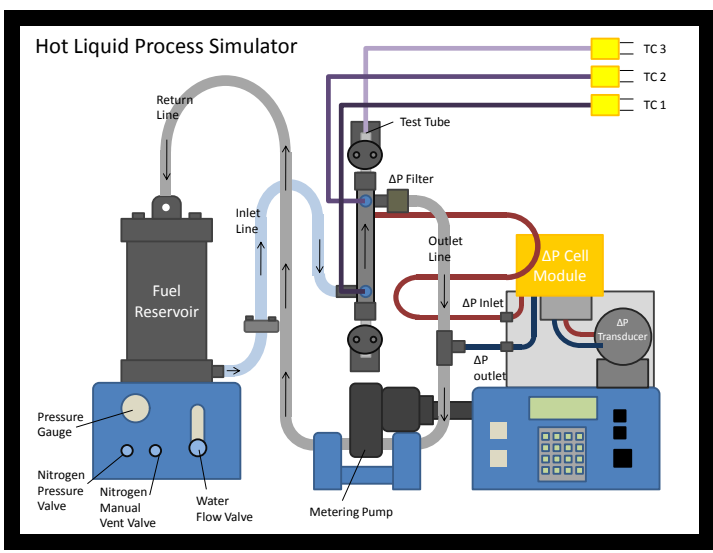

Figure 10: Hot Liquid Process Simulator

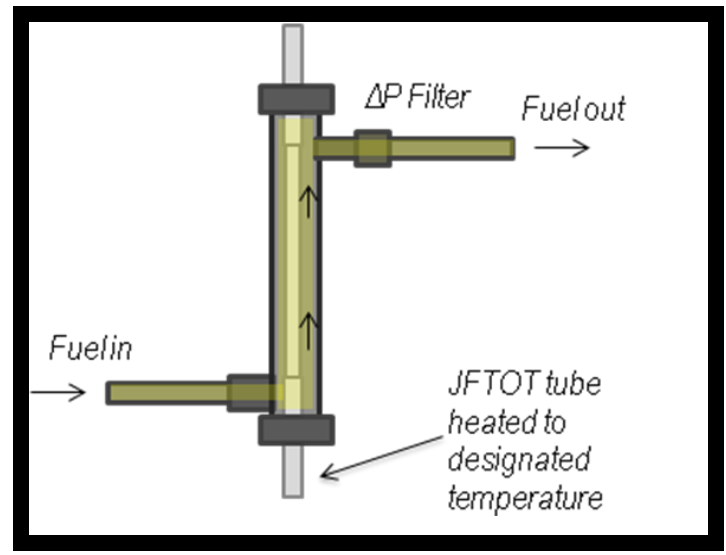

Figure 11: Fuel flowing over a heated JFTOT tube.

The HLPS components are mainly constructed of 316 stainless steel. The HLPS reservoir can hold up to $1 \mathrm{~L}$ of fuel and is capable of testing fuel fouling tendencies at conditions up to $650{ }^{\circ} \mathrm{C}$. Various types of heater tubes can be used in order to reach temperature requirements for each individual test. JFTOT requires the use of an Aluminum tube, which has an upper limit of $380{ }^{\circ} \mathrm{C}$, whereas stainless steel tubes can be used up the $650{ }^{\circ} \mathrm{C}$ limit. The Visual Tube Rater (VTR) color chart is designed for the standardized aluminum tubes. While steel or stainless steel tubes can be used for tests requiring higher temperatures up to $650{ }^{\circ} \mathrm{C}$, the VTR may not be a valid test with these types of tubes due to differences in tube properties.

Thermal stability test results for F-T fuel has shown to have breakpoint values of $380{ }^{\circ} \mathrm{C}$, but only because of failing the JFTOT because of tube color. Due to the fact that at elevated temperatures, steel tubes must be used, it is unclear if the fuels are actually forming particulates on the tubes, or if the tubes are just changing colors because of material properties of steel. Figure 12 shows breakpoint temperatures and failure types of blended Jet-A/ F-T fuel compositions.

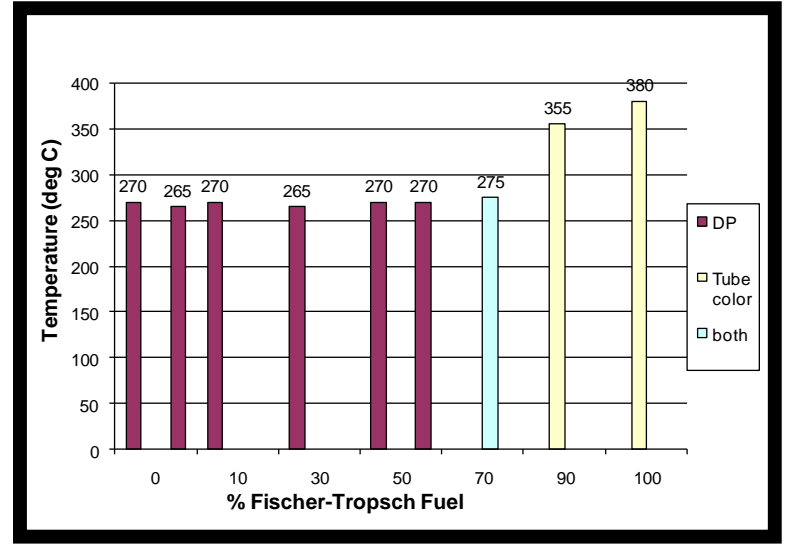

Figure 12: Breakpoint failures of blended Jet-A/ F-T fuel

At elevated temperatures, the F-T fuel is failing solely on tube color and not on pressure drop. Typically the fuel will fail on pressure drop before tube color. These results have led to the investigation of the JFTOT tube materials at elevated temperatures.

\section{FuEl Fouling RESEARCH}

Due to the uncertainty of the current thermal stability results for alternative type fuels, fuel fouling research will be performed with a Horiba "Auto SE Ellipsometer". ${ }^{12}$ Fuel fouling profiles and particulate formation will be investigated along JFTOT tubes for aluminum, steel and stainless steel tubes to determine if particulates are actually being formed at elevated temperatures, or if the discoloration of the tubes is solely from the heated test cycle. The outcome of this research may lead to further investigation of breakpoint test standards for alternative type fuels due to their low aromatic content and high thermal stability. Research is expected to begin in July 2011. Figure 13 shows the Auto SE Ellipsometer.

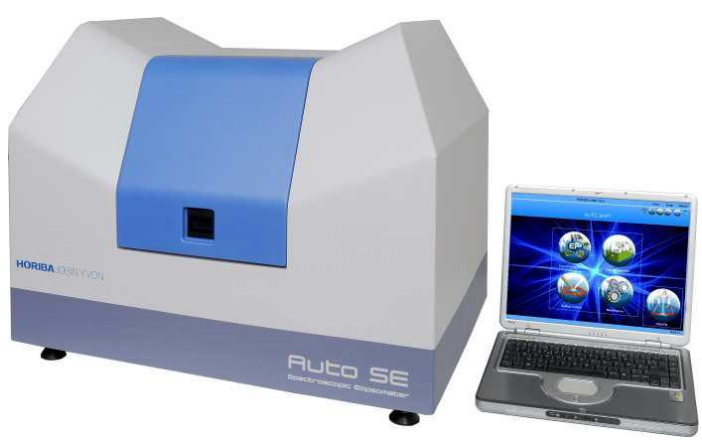

Figure 13: Horiba Auto SE Ellipsometer ${ }^{12}$ 
X. FACILITY CAPABILITY SUMMARY

\begin{tabular}{|c|c|}
\hline F-T reactors & \\
\hline Reactor capacity & 1 Liter \\
\hline Total \# of reactors & 3 \\
\hline $\begin{array}{l}\text { Materials of } \\
\text { Construction }\end{array}$ & $316 \mathrm{SS}$ \\
\hline Operating pressure & $0-450$ psig \\
\hline Operating temperature & $0-280^{\circ} \mathrm{C}$ \\
\hline Gas feeds & $\begin{array}{l}\mathrm{UHP} \mathrm{H} 2, \mathrm{UHP} \mathrm{CO}, \mathrm{N} 2 \\
\text { and Argon }\end{array}$ \\
\hline Gas feed flow rates & 0-120 SLPH per feed \\
\hline Shop Air & 125 psig \\
\hline Reactor motor speed & $100-1250 \mathrm{rpm}$ \\
\hline Catalyst type & Cobalt or Iron \\
\hline \multicolumn{2}{|l|}{ Fixed Bed Reactor } \\
\hline Material of Construction & $316 \mathrm{SS}$ \\
\hline Operating pressure & $0-225$ psig \\
\hline Operating temperature & $0-430^{\circ} \mathrm{C}$ \\
\hline Gas feeds & $\begin{array}{l}\text { UHP H2, UHP CO, N2 } \\
\text { and Argon }\end{array}$ \\
\hline Gas feed flow rates & 0-120 SLPH per feed \\
\hline \multicolumn{2}{|l|}{$\begin{array}{c}\text { Hot Liquid Process } \\
\text { Simulator } \\
\end{array}$} \\
\hline Materials of Construction & $316 \mathrm{SS}$ \\
\hline Reservoir capacity & 1 Liter \\
\hline $\begin{array}{l}\text { Amount of fuel used per } \\
\text { test }\end{array}$ & $600 \mathrm{ml}$ \\
\hline Pressure & 500 psig \\
\hline Maximum temperature & $650^{\circ} \mathrm{C}$ \\
\hline Flow rate range & 0.25 to $5 \mathrm{ml} / \mathrm{min}$ \\
\hline Single test duration & 4 hours \\
\hline \multicolumn{2}{|l|}{$\begin{array}{c}\text { Gas } \\
\text { Chromatography } \\
\end{array}$} \\
\hline $\begin{array}{l}\text { Agilent 3000A Micro } \\
\text { GC ( gas) }\end{array}$ & $\begin{array}{l}\text { TCD, C1 to C4 } \\
\text { compounds }\end{array}$ \\
\hline $\begin{array}{l}\text { Agilent } 6890 \text { GCs } \\
\text { (liquid) }\end{array}$ & $\begin{array}{l}\text { FID, C6 to C80 } \\
\text { compounds }\end{array}$ \\
\hline
\end{tabular}

\section{CONCLUding REMARKS}

Fischer-Tropsch synthesis converts syngas derived into synthetic crude from non-petroleum sources such as coal, natural gas, and renewable biomass. By using the F-T reactors to develop novel catalysts coupled with the development of the innovative F-T process, new pathways can be identified to produce large quantities of consumable fuel along with reduced fuel production costs.

Future research plans include the testing of novel catalysts with unique types of supports and promoters. Catalyst developments will be performed at NASA Glenn along with universities and external businesses specializing in catalyst development.
Thermal Stability tests will also continue for various types of fuels to determine the breakpoint of each fuel prior to testing a new fuel in a combustion test facility. Fuel fouling research will also be performed to determine JFTOT validity for alternative type fuels.

\section{REFERENCES}

[1] Klettlinger, J., Yen ,C., Nakley ,L., Surgenor, A., "Fischer-Tropsch Cobalt Catalyst Activation and Handling through Wax Enclosure Methods", AICHE Spring Meeting \& $7^{\text {th }}$ Global Congress of Process Safety paper, March 2011.

[2] Edwards, T., Minus, D, Harrison, W., Corporan, E., "Fischer-Tropsch Jet Fuels- Characterization for Advanced Aerospace Applications

[3] Surgenor, A, Klettlinger, J, Yen, C., Nakley, L., "Alternative Fuels Research Facility," AICHE Spring Meeting \& $7^{\text {th }}$ Global Congress on Process Safety paper ID\#211849, March 2011.

[4] Harrison, W.E., Edwards, T. and Anderson, S.D. (1993) "U.S. Air Force Improved JP-8 Development Program -An Overview", 2d International Symposium on Aviation Turbine Fuel Specifications, 1993, May 11-13.

[5]http://aiche.confex.com/aiche/s07/preliminaryprogram/abstract_80933.htm

[6] http://www.pressureproductsindustries.com/reactors/FCSeries.html

[7] Baker Hughes, (February 2011), POLYWAX Polyethylenes. http://www.bakerhughes.com/assets/media/technicaldatasheets/4c97b7f7f a7e1c37f1000015/file/28729_polywax-sheet-2-5-10.pdf.pdf\&fs=302313

[8] Bulzan, Dan, Bruce Anderson, et. al. "Gaseous and Particulate Emissions Results of the NASA Alternative Fuel Experiment (AAFEX)", Proceedings of ASME Turbine Expo 2010: Power for Land, Sea and Air, GT2010, June 14-18, Glasgow, Scotland.

[9] Davis, B., Center for Applied Energy Research(CAER), University of Kentucky

[10] Klettlinger, J., Yen ,C., Nakley ,L., Surgenor, A., Yen, C., "Thermal Stability Testing of a Fischer-Tropsch Fuel and Various Blends With Jet A "NASA/TM 216370, May 2010 http://gltrs.grc.nasa.gov/reports/2010/TM-2010-216370.pdf

[11] http://www.paclp.com/Lab_Instruments/Brand/Alcor

[12] www.horiba.com/scientific/products/ellipsometers/spectroscopic/autose/auto-se-482 